\title{
BRAND POSITIONING DAN TRUST TERHADAP LOYALITAS NASABAH (Studi Pada Nasabah BPR JATIM Cabang Batu)
}

\author{
Dona Pambudi Wijayana \\ Bank Perkreditan Rakyat Jawa Timur \\ E-mail: pambudi.dona89@gmail.com
}

\begin{abstract}
The purpose of this study was to the positioning of brand loyalty, how positioning the brand to trust, how to trust in the loyalty and how to position the brand loyalty through customer confidence in their loan JATIM on Branch of Batu City. Sampling obtained from 100 respondents credit customers BPR Jatim on Branch of Batu City, studies using Patial Least Square ( PLS ) and the obtained results of research are positioning the brand effect on loyalty, positioning the brand effect on confidence, trust affect the loyalty and positioning the brand effect on loyalty through trust BPR JATIM on Branch of Batu City.
\end{abstract}

Keywords: Brand Positioning, Loyalty, Trust.

\begin{abstract}
Abstrak
Penelitian ini bertujuan untuk mengetahui bagaimana pemosisian merek terhadap loyalitas, bagaimana pemosisian merek terhadap kepercayaan, bagaimana kepercayaan terhadap loyalitas dan bagaimana pemosisian merek terhadap loyalitas melalui kepercayaan pada nasabah kredit BPR JATIM Cabang Batu. Pengambilan sampling didapat dari 100 responden nasabah kredit BPR JATIM Cabang Batu, penelitian menggunakan Patial Least Square (PLS) dan didapat hasil Penelitian adalah pemosisian merek berpengaruh terhadap loyalitas, pemosisian merek berpengaruh terhadap kepercayaan, kepercayaan berpengaruh terhadap loyalitas dan pemosisian merek berpengaruh terhadap loyalitas melalui kepercayaan pada BPR JATIM Cabang Batu.
\end{abstract}

Kata Kunci: Kepercayaan, Loyalitas, Pemosisian Merek 
Ekonomika-Bisnis,Vol. 07 No. 02 Bulan Juli Tahun 2016 Hal 115-124

\begin{abstract}
Membangun suatu merek yang kuat merupakan tujuan dari setiap perusahaan karena merek merupakan aset bagi perusahaan, dimana diperlukan adanya suatu ikatan antara merek dan konsumen.
\end{abstract}

Pemosisian merek (Brand positioning) adalah keputusan utama dalam pemasaran yang bertujuan untuk membangun citra produk atau jasa di benak pelanggan. Brand positioning bertujuan agar perusahaan mempunyai nilai khusus yang dapat dibedakan dengan pesaing lainnya, untuk membuat sesuatu hal yang khas atau yang berkesan di dalam benak atau pikiran konsumen, Agar konsumen mudah ingat kepada perusahaan, seperti Menurut Kotler (2002) tepat didefinisikan "positioning" sebagai tindakan merancang menawarkan dan citra perusahaan untuk menempati posisi yang berarti dan berbeda dalam benak target pelanggan.

Bank dapat meningkatkan nilai pelanggan dengan memperkuat posisi merek di benak nasabah agar nasabah percaya terhadap merek dan loyal terhadap perusahaan. Dalam proses pemilihan dan pembelian, konsumen akan selalu membeli produk-produk yang dibutuhkan dan sesuai harapan mereka, jika merek yang dibuat oleh bank dapat posisi di benak nasabah yang akhirnya membentuk suatu kepemilikan reputasi di pikiran nasabah, maka nasabah akan semakin yakin dengan pilihannya dan nasabah akan memiliki kepercayaan pada merek, menyukai merek serta menganggap merek tersebut sebagai bagian dari dirinya. Sehingga kesetiaan mereka akan lebih mudah untuk dibentuk. Kepercayaan merek akan menentukan kesetiaan konsumen terhadap merek dan kepercayaan berpotensi menciptakan hubunganhubungan yang bernilai tinggi. Bagi perbankkan, loyalitas suatu nasabah merupakan kunci agar perusahaan itu tetap bisa bertahan dari para pesaingpesaingnya.

Di dalam dunia Perbankkan sebagai perusahaan jasa, nasabah merupakan sekelompok individu yang penting dalam kemajuan bank, berbagai kegiatan dilakukan namun terkadang tidak dapat memberikan manfaat yang besar terhadap perkembangan bank jika tidak adanya rasa kepercayaan yang timbul dari nasabah atau calon nasabah, dengan menggunakan ciri-ciri kepribadian di pemosisian merek membantu perusahaan meningkatkan konsumen preferensi, loyalitas dan kepercayaan (Lerzan and Özsomer, 2007). Kepercayaan juga salah satu hal yang dibentuk di dalam benak para nasabah suatu bank, karena bank merupakan perusahaan jasa yang sifatnya menyimpan dana dari masyarakat dan menyalurkan dana ke masyarakat untuk kebutuhan modal usaha.

Bank adalah bentuk perusahaan yang berfokus terhadap kepercayaan nasabah. Kepercayaan ini sangat menentukan bank dimata nasabah. Kepercayaan timbul dari suatu proses yang membutuhkan waktu lama sampai kedua belah pihak saling mempercayai. Kepercayaan merek akan menentukan kesetiaan konsumen terhadap merek dan kepercayaan berpotensi menci-ptakan hubunganhubungan yang bernilai tinggi (Morgan and Hunt, 1994) . Timbulnya kepercayaan merek juga dibutuhkan sebagai komitmen pelanggan untuk tidak hanya melakukan pembelian ulang, melainkan untuk loyal terhadap merek dan memunculkan kedekatan 
emosional dan psikologis dari seorang konsumen terhadap merek suatu produk.

Penelitian yang dilakukan Soegoto (2009) menunjukkan bahwa semakin tinggi kinerja nilai dan kepercayaan nasabah pada suatu bank, maka makin tinggi pula tingkat loyalitas nasabah terhadap bank. Jika suatu bank dapat meningkatkan suatu kepercayaan ke nasabah akan dapat meningkatkan loyalitas nasabah terhadap bank. Walaupun bank menawarkan produk yang sangat istimewa terhadap nasabah namun tidak adanya rasa percaya terhadap bank yang akan membuat rasa loyal, dapat menimbulkan rasa enggan bekerja sama pada suatu bank dalam bentuk apapun.

Kepercayaan akan dibangun oleh bank karena faktor ini berdampak pada loyalitas nasabah seperti menurut Ruben. and Nicholas. (2005). Kesetiaan pelanggan merupakan suatu kondisi dimana pelanggan melakukan pem-belian ulang dimasa yang akan datang, menurunkan elastisitas harga, meng-hambat pesaing menarik pelanggan karena pelanggan enggan berpindah, menurunkan biaya penanganan ketidak-sesuaian produk/ jasa, menu-runkan biaya dan waktu transaksi berikutnya, menurunkan biaya pencarian pelanggan baru karena pelanggan akan cenderung menginformasikan kepada calon pelanggan lainnya.

Pentingnya rasa kepercayaan dan suatu pemosisian merek di benak nasabah untuk kemajuan bank, hal ini dapat dilakukan dan diwujudkan pada setiap tindakan yang dilakukan pada bank. Dari pembahasan di atas menariknya brand positioning dan kepercayaan ini perlu diteliti secara mendalam apakah benar dengan dibentuknya brand positioning dan kepercayan nasabah dapat membentuk suatu loyalitas kepada Bank Umkm Jawa Timur Cabang Batu. Bank Umkm Jawa Timur Cabang Batu adalah sebagai obyek dari penelitian ini.

Pemosisian merek dapat diukur dengan menggunakan beberapa indikator. Menurut Susanto and Himawan (2004) Positioning adalah posisi relatif merek kita di antara tebaran merek pesaing di dalam persepsi konsumen. Apa yang dilakukan pesaing akan berpengaruh pada konfigurasi posisi ini. Oleh karena itu, harus dilakukan pemantauan dan evaluasi terhadap posisi merek kita, apakah posisi tersebut perlu diperkuat atau justru diubah.

Ada lima prinsip yang dapat dipakai untuk melihat efektifitas positioning yaitu ; 1. Nilai, terfokus pada manfaat yang diterima pelanggan. Intinya adalah nilai apa yang diterima oleh pasar sasaran dari posisi merek yang dimiliki perusahaan; 2. Keunikan, pada intinya membawa sesuatu yang tidak dimiliki oleh pesaing sehingga posisi merek perusahaan memberikan penawaran yang berbeda dibandingkan pesaing; 3. Kredibilitas, menunjukan seberapa besar kredibilitasnya di mata konsumen dan menurut (poeindriasari, 2012) kredibilitas adalah kualitas, kapabilitas, atau kekuatan. Pada (Djati and Ferrinadewi, 2004) kredibilitas adalah kemampuan merek atau produk untuk memenuhi syarat-syarat pertukaran dalam bentuk kinerja yang diharapkan; 4. Berkelanjutan, intinya memaksimalkan waktu rentang waktu lamanya menempati posisi dalam persaingan; 5. Kesesuaian, yakni kesesuaian antara posisi merek dengan perusahaan. 
Kartajaya (2004) menyebutkan Tingkat kepercayaan dapat diukur melalui beberapa faktor yang daat menjadi indikator antara lain kejujuran dalam bertransaksi, tanggung jawab perusahaan terhadap konsumen dan masih banyak lagi. Juga (Kim et al., 2003 ) menyatakan bahwa ability meliputi kompetensi, pengalaman, pegesahan institusional, dan kemampuan dalam ilmu pengetahuan.

Pada loyalitas dikatakan oleh Zeithaml (1996) Tujuan akhir keberhasilan perusahaan menjalin hubungan dengan pelanggan adalah membentuk loyalitas yang kuat, dimensi loyalitas pelanggan yang di pakai adalah; $1 . \quad$ Say Positive Things, mengatakan hal yang positif tentang produk yang telah di konsumsi dalam hal produk yang dihasilkan selalu berkualitas; 2. Recommend Friend, produk yang telah dikonsumsi direkomendasikan kepada orang lain, dalam hal ini selalu mengajak orang lain untuk membeli; 3. Continue Purchasing, pembelian yang dilakukan secara terus menerus terhadap produk yang telah dikonsumsi.

Penelitian terdahulu menyatakan brand positioning mempunyai pengaruh yang positif terhadap loyalitas pelanggan. Pembuktian brand posi-tioning berpengaruh terhadap keper-cayaan seperti yang di tulis oleh (Kartajaya, 2006). Positioning merupakan upaya untuk mempengaruhi pikiran konsumen dengan penawaran perusahaan kita. Positioning strategi untuk mengarahkan pelanggan.

Pembuktian kepercayaan berpengaruh terhadap loyalitas yang dilakukan oleh Wulan et al. (2014) . Pada penelitian (Flavian and Guinalıu, 2006) ini yang intinya membahas tentang bisnis online atau website dan memberikan penjelasan bahwa kepercayaan adalah modal utama untuk membangun loyalitas pelanggan dan didukung oleh adanya keamanan data pelanggan agar terciptanya loyalitas yang semakin besar. Inti dari kesuksesan bisnis online atau bisnis dengan media website adalah terwujudnya rasa percaya yang didukung oleh keamanan data pribadi.

Brand positioning berpengaruh terhadap loyalitas melalui kepercayaan dikatakan oleh Ruben and Nicholas (2005). Adapun faktor untuk mempengaruhi loyalitas nasabah adalah faktor yaitu kepercayaan (trust), kepercayaan timbul dari suatu proses yang lama sampai kedua belah pihak saling mempercayai. Penelitian Lerzan and Özsomer (2007) dengan menggunakan ciri-ciri kepribadian di pemosisian merek membantu perusahaan meningkatkan preferensi konsumen, kepercayaan dan loyalitas.

Kepercayaan dan komitmen merupakan variabel mediasi dalam hubungan jangka panjang antara perusahaan dengan konsumen (Morgan and Hunt, 1994). Penelitian yang di lakukan Tezide et al. (2001) juga membuktikan bahwa kepercayaan dan kepuasan akan mempengaruhi hubungan dengan konsumen dan loyalitas.

\section{Metode Penelitian}

Penelitian ini mengukur hubungan antara pengaruh variabel independent pemosisian merek (brand positioning) dan kepercayaan (trust) terhadap variabel dependent (loyalitas nasabah) baik secara parsial maupun simultan yang ada dalam hipotesis tersebut. 


Pada penelitian ini maka
populasi adalah para nasabah yang
telah bekerja sama dengan BPR
ditolerir sebesar 10\%. Peneliti
menggunakan rumus Solvin karena di
penelitian ini populasi telah diketahui
jumlahnya yaitu 1.500 orang dari
nasabah kredit per April 2015.
Berdasarkan perhitungan di atas, maka
jumlah sampel yang digunakan dalam
penelitian ini minimal 93 responden

\section{Hasil Penelitian dan Pembahasan}

Berdasarkan hasil uji validitas dan reabilitas yang telah dilakukan terhadap 100 reponden, maka didapatkan hasil pada tabel 1 .

Tabel 2 menunjukan hasil pengukuran data dengan menggunakan composite reliability, untuk menentukan apakah konstruk memiliki reliabilitas yang tinggi atau tidak. Nilai composite reliability > 0,70 . menyatakan bahwa kontruk tersebut reliable.

Nilai koefisien jalur yang didapatkan dari Partial Least Square (PLS) yang disajikan pada gambar. 2 merupakan hasil pengolahan data primer yang didapatkan peneliti pada objek penelitian yang kemudian digunakan untuk penguji pengaruh vari abel eksogen terhadap variabel endogen.

Dari tabel 3 dapat dilihat terdapat hubungan yang positif dengan koefisien parameter $(0,221)$ dan signifikan antara hubungan brand positioning (X1) terhadap loyalitas (Y) karena memiliki nilai t- statistik sebesar $(2,138)$ lebih besar dari nilai $t$ tabel $(1,96)$, maka hipotesis $\mathrm{H} 2$ dapat disimpulkan bahwa terdapat pengaruh positif dan signifikan antara Brand Positioning (X1) terhadap Loyalitas (Y) dengan toleransi kesalahan (apha)

\begin{abstract}
JATIM Cabang Batu. Pada penelitian ini peneliti menggunakan batas kesalahan yang sebesar 5\%. Arah hubungan positif menyatakan bahwa semakin baik Brand Positioning (X1) yang terdapat pada perusahaan maka akan meningkatkan Loyalitas (Y), hipotesis 1 diterima.
\end{abstract}

Hal ini sejalan dengan pernyataan hasil pengujian hipotesis bahwa brand positioning mempunyai pengaruh yang positif terhadap loyalitas pelanggan (Gunawan, 2013). Penelitian dilakukan dalam pedagang eceran pemosisian merek mempengaruhi loyalitas pelanggan dan kinerja (Ailawadi and Keller, 2004). Dengan pernyataan di atas brand positioning adalah sesuatu kegiatan dimana dapat menciptakan di dalam benak nasabah agar menjadi loyal terhadap BPR JATIM Cabang Batu.

Hasil pengujian pengaruh pada brand positioning (X1) terhadap kepercayaan (X2) disajikan dalam tabel 3 Dapat dilihat terdapat hubungan yang positif dengan koefisien parameter $(0,536)$ dan signifikan antara hubungan brand positioning (X1) terhadap Hasil pengujian pengaruh pada brand positioning (X1) terhadap kepercayaan (X2) disajikan dalam tabel 3 Dapat dilihat terdapat hubungan yang positif dengan koefisien parameter $(0,536)$ dan signifikan antara hubungan brand positioning (X1) terhadap kepercayaan (X2) karena memiliki nilai t- statistik sebesar(11,597) lebih besar dari nilai $t$ tabel $(1,96)$, maka hipotesis H1 dapat disimpulkan bahwa terdapat pengaruh positif dan signifikan antara Pemosisian Merek (brand positioning) (X1) terhadap Kepercayaan (X2) dengan toleransi kesalahan (apha) 
Ekonomika-Bisnis,Vol. 07 No. 02 Bulan Juli Tahun 2016 Hal 115-124

\begin{tabular}{|c|c|c|c|}
\hline \multicolumn{2}{|c|}{$\begin{array}{l}\text { sebesar 5\%. Arah hubungan positif } \\
\text { menyatakan bahwa semakin baik } \\
\text { brand positioning (X1) yang terdapat } \\
\text { pada perusahaan maka akan } \\
\text { meningkatkan kepercayaan (X2), }\end{array}$} & \multicolumn{2}{|c|}{$\begin{array}{l}\text { hipotesis } 2 \text { diterima Hal ini didukl } \\
\text { oleh penelitian sebelumnnya yang ha } \\
\text { temuannya konsisten seperti yang } \\
\text { tulis oleh (Kartajaya, 2006). }\end{array}$} \\
\hline \multicolumn{4}{|l|}{ Tabel. 1 Uji Validitas } \\
\hline Variabel & Indikator & Outer Loading & Keterangan \\
\hline \multirow[t]{5}{*}{ Brand positioning } & $\mathrm{X} 1.1$ & 0,665953 & Valid \\
\hline & $\mathrm{X} 1.2$ & 0,634483 & Valid \\
\hline & $\mathrm{X} 1.3$ & 0,699326 & Valid \\
\hline & $\mathrm{X} 1.4$ & 0,678063 & Valid \\
\hline & $\mathrm{X} 1.5$ & 0,577277 & Valid \\
\hline \multirow[t]{3}{*}{ Trust } & $\mathrm{X} 2.1$ & 0,753997 & Valid \\
\hline & $\mathrm{X} 2.2$ & 0,792521 & Valid \\
\hline & $\mathrm{X} 2.3$ & 0,705925 & Valid \\
\hline \multirow[t]{3}{*}{ Loyalty } & Y.1 & 0,650411 & Valid \\
\hline & Y.2 & 0,807609 & Valid \\
\hline & Y.3 & 0,777513 & Valid \\
\hline
\end{tabular}

Sumber, data primer, diolah tahun 2016

Tabel. 2 Uji reliabilitas

\begin{tabular}{|c|c|c|c|c|c|}
\hline \multicolumn{3}{|l|}{ Variabel } & \multicolumn{3}{|c|}{ Composite Reliability } \\
\hline \multicolumn{3}{|l|}{ Brand Positioning } & \multicolumn{3}{|c|}{0,786757} \\
\hline \multicolumn{3}{|l|}{ Trust } & \multicolumn{3}{|c|}{0,795398} \\
\hline \multicolumn{3}{|l|}{ Loyalty } & \multicolumn{2}{|c|}{0,791034} & \\
\hline \multicolumn{6}{|c|}{ Sumber, data primer, diolah tahun 2016} \\
\hline \multicolumn{6}{|c|}{ Tabel 3. Pengujian Hipotesis } \\
\hline & $\begin{array}{l}\text { Original } \\
\text { Sample (O) }\end{array}$ & $\begin{array}{l}\text { Sample } \\
\text { Mean (M) }\end{array}$ & $\begin{array}{l}\text { Standard } \\
\text { Deviation } \\
(\mathrm{STDEV})\end{array}$ & $\begin{array}{l}\text { Standard } \\
\text { Error } \\
\text { (STERR) }\end{array}$ & $\begin{array}{c}\text { T Statistics } \\
(|\mathrm{O} / \mathrm{STERR}|)\end{array}$ \\
\hline $\begin{array}{l}\text { Brand Positioning } \\
\text { terhadap loyalitas }\end{array}$ & 0,221271 & 0,223414 & 0,103481 & 0,103481 & 2,138274 \\
\hline $\begin{array}{l}\text { Brand Positioning } \\
\text { terhadap } \\
\text { Kepercayaan }\end{array}$ & 0,536531 & 0,540136 & 0,046261 & 0,046261 & 11,597853 \\
\hline $\begin{array}{l}\text { Kepercayaan } \\
\text { terhadap loyalitas }\end{array}$ & 0,210526 & 0,212800 & 0,090703 & 0,090703 & 2,321055 \\
\hline
\end{tabular}

Sumber : Data Primer, diolah tahun 2016 
Positioning merupa-kan upaya untuk mempengaruhi pikiran konsumen dengan penawaran perusaha-an kita. Positioning strategi untuk mengarahkan pelanggan. Positioning adalah upaya membangun kepercayaan dimata konsumen bahwa produk kita memang layak dipercaya dan kompeten. dengan menggunakan ciriciri kepribadian di pemosisian merek membantu perusahaan meningkatkan konsumen preferensi, kepercayaan dan loyalitas di buktikan oleh ( Aksoy dan Özsomer , 2007).

Hasil pengujian pengaruh pada brand positioning (X1) terhadap kepercayaan (X2) disajikan dalam tabel 3, dapat dilihat terdapat hubungan yang positif dengan koefisien parameter $(0,210)$ dan signifikan antara hubungan Kepercayaan (Trust) (X2) terhadap loyalitas (Y) karena memiliki nilai t- statistik sebesar $(2,321)$ lebih besar dari nilai t tabel $(1,96)$, maka hipotesis $\mathrm{H} 3$ dapat disimpulkan bahwa terdapat pengaruh positif dan signifikan antara Kepercayaan (X2) terhadap Loyalitas (Y) dengan toleransi kesalahan (apha) sebesar 5\%. Arah hubungan positif menyatakan kepercayaan terbukti mempengaruhi antara brand positioning terhadap loyalitas. maka hipotesis $\mathrm{H} 4$ dapat disimpulkan bahwa kepercayaan (X2) memediasi brand positioning (X1) terhadap loyalitas (Y), dengan demikian hipotesis $\mathrm{H} 4$ diterima.

Penelitian ini juga telah di buktikan sebelumnya dipenelitian Lerzan and Özsomer (2007) dengan menggunakan ciri-ciri kepribadian di pemosisian merek membantu perusahaan meningkatkan preferensi konsumen, kepercayaan dan loyalitas. Dan kepercayaan dan komitmen merupakan variabel mediasi dalam bahwa semakin baik Kepercayaan (X2) yang terdapat pada perusahaan maka akan meningkatkan Loyalitas (Y), hipotesis 3 diterima.

Penelitian ini konsisten dengan penelitian yang dilakukan oleh Wulan et al. (2014) .Variabel kepercayaan merek juga berpengaruh terhadap loyalitas merek notebook Toshiba, dimana pengaruh yang diberikan variabel kepercayaan merek terhadap variabel loyalitas merek. juga pada penelitian (Flavian and Guinaliu, 2006) yang intinya membahas tentang bisnis online atau website, dan memberikan penjelasan bahwa kepercayaan adalah modal utama untuk membangun loyalitas pelanggan dan didukung oleh adanya keamanan data pelanggan agar terciptanya loyalitas yang semakin besar.

Pengaruh brand positioning terhadap loyalitas melalui kepercayaan (menggunakan tabel bantu test sobel: http://people.ku.edu/preacher/sobel/sob el.htm. Hasil dari tabel tersebut menun-jukan nilai $t$ hitung yang dibandingkan dengan nilai t tabel yaitu $2.348 \geq 1,96$ dan nilai $\mathrm{p}=0,018$ $(\mathrm{p}<0.05)$ maka

hubungan jangka panjang antara perusahaan dengan konsumen pada penelitian (Morgan and Hunt, 1994). Juga pada Penelitian yang di lakukan Tezide et al. (2001) juga membuktikan bahwa kepercayaan dan kepuasan akan mempengaruhi hubungan dengan konsumen dan loyalitas.

\section{Penutup}

Berdasarkan hasil penelitian, analisis data dan pembahasan yang telah dilakukan, dapat disimpulkan beberapa hal. Adapun yang pertama, pemosisian merek (Brand Positioning) pada BPR JATIM/Bank Umkm Jawa 
Timur Cabang Batu baik. Hasil pemosisian merek (Brand Positioning) BPR JATIM/Bank Umkm Jawa Timur Cabang Batu sudah berjalan serta memberikan pengaruh untuk kelangsungan BPR JATIM/Bank Umkm Jawa Timur Cabang Batu dan dapat dikategorikan baik. Pada penelitian ini perlu dipertahankan oleh BPR JATIM/Bank Umkm Jawa Timur adalah kredibilitas yang mencangkup kualitas dan kemampuan dalam bertransaksi dengan nasabah dan perlu dikembangkann atau di tingkatkan nilai, keunikan, berkelanjutan dan kesesuaian di BPR JATIM pada fasilitas permodalan usaha dan transaksi.

Kedua, kepercayaan nasabah pada BPR JATIM/Bank Umkm Jawa Timur Cabang Batu baik. kepercayaan yang terjalin antara nasabah dan BPR JATIM/Bank Umkm Jawa Timur Cabang Batu dalam kategori baik. pada penelitian ini yang kurang ditingkatkan oleh BPR JATIM Cabang Batu yaitu meningkatkan kejujuran dan pengalaman untuk memperkuat kepercayaan nasabah, sedangkan yang perlu dipertahankan oleh BPR JATIM Cabang Batu untuk dapat terus mempertahankan tanggung jawab yang dapat mempengaruhi kepercayaan nasabah.

Ketiga, loyalitas (Loyalty) Nasabah pada BPR JATIM/Bank Umkm Jawa Timur adalah dalam keadaan baik. BPR JATIM Cabang Batu dapat membentuk loyalitas nasabah kepada perusahaannya, dampak loyalitas nasabah yang baik pula kepada perusahaan khususnya BPR JATIM/ Bank Umkm Jawa Timur Cabang Batu.

Kelima, pemosisian Merek (Brand Positioning) berpengaruh dimana loyalitas (Loyalty) nasabah terhadap perusahaan merupakan hal yang dapat memberikan dampak keberhasilan dan kehidupan BPR JATIM/ Bank Umkm Jawa Timur Cabang Batu. Dalam penelitian ini yang perlu dipertahankan adalah selalu membuat agar nasabah mengundang orang lain atau teman untuk bekerja sama dengan BPR JATIM/Bank Umkm Jawa Timur Cabang Batu. Sedangkan yang kurang ditingkatkan adalah menciptakan suatu hal yang dapat mendorong nasabah untuk selalu mengatakan hal positif kepada orang lain dan akan melakukan transaksi secara terus menerus kepada BPR JATIM/Bank Umkm Jawa Timur Cabang Batu.

Keempat, pemosisian merek (Brand Positioning) berpengaruh terhadap Loyalitas (Loyalty) Nasabah BPR JATIM/ Bank Umkm Jawa Timur Cabang Batu. Hasil pemosisian merek sangatlah mempengaruhi pembentukan rasa loyal nasabah kepada BPR JATIM Cabang Batu. Dapat dikatakan juga bahwa pemosisian merek yang baik akan memberikan merek melalui kepercayaan dapat menimbulkan dan meningkatkan rasa loyal pada nasabah terhadap suatu perusahaan khususnya pada BPR JATIM Cabang Batu. Dapat dikatakan bahwa suatu tindakan pemosisian merek melalui kepercayaan dapat menimbulkan dan meningkatkan loya-litas nasabah pada BPR JATIM/Bank Umkm Jawa Timur Cabang Batu.

terhadap kepercayaan (Trust) Nasabah BPR JATIM/Bank Umkm Jawa Timur Cabang Batu. Dapat dikatakan pemosisian merek dapat menimbulkan rasa percaya terhadap suatu perusahaan khususnya pada BPR JATIM Cabang 
Batu. Dapat dikatakan bahwa suatu tindakan pemosisian merek dapat menimbulkan dan meningkatkan keper-cayaan nasabah BPR JATIM/Bank Umkm Jawa Timur Cabang Batu.

Keenam, kepercayaan (Trust) berpengaruh terhadap loyalitas (Loyalty) Nasabah BPR JATIM/Bank Umkm Jawa Timur Cabang Batu. Dapat dikatakan kepercayaan dapat menimbulkan rasa loyalitas nasabah terhadap suatu perusahaan khususnya pada BPR JATIM Cabang Batu. Dapat juga dikatakan bahwa suatu dorongan tindakan rasa percaya pada nasabah dapat menimbulkan dan meningkatkan rasa loyal pada nasabah BPR JATIM/Bank Umkm Jawa Timur Cabang Batu.

Ketujuh, pemosisian Merek (Brand Positioning) berpengaruh terhadap loyalitas (Loyalty) Nasabah BPR JATIM/Bank Umkm Jawa Timur Cabang Batu melalui kepercayaan (Trust). Dapat dikatakan pemosisian merek melalui kepercayaan dapat menimbulkan dan meningkatkan rasa loyal pada nasabah terhadap suatu perusahaan khususnya pada BPR JATIM Cabang Batu. Dapat dikatakan bahwa suatu tindakan pemosisian merek melalui kepercayaan dapat menimbulkan dan meningkatkan loyalitas nasabah pada BPR JATIM/Bank Umkm Jawa Timur Cabang Batu.

\section{DAFTAR PUSTAKA}

Ries, A. L. \& Trout, J. 2000. Positioning: The battle for your mind. Newyork: McGrawHill.

Ruben., C. C. \& Nicholas., G. P. 2005. Service quality, relationship satisfaction, trust, commitment
Ailawadi, K. L. \& Keller, K. L. 2004. Understanding retail branding: conceptual insights and research priorities. Journal of Retailing, 80.

Gunawan, A. I. 2013. Pengaruh brand positioning terhadap loyalitas. Pelanggan surat kabar pikiran rakyat pendidikan ekonomi, 1 .

Kartajaya, H. 2004. Positioning, Diferensiasi, dan Brand. Jakarta: Pt. Gramedia Pustaka Utama.

Kartajaya, H. 2006. On Positioning. Bandung: Mizan.

Kim, D. J., Ferrin \& Rao 2003 Antecedent of Consumer Trust in B-to-C Electronic Commerce. Proceedings of Ninth Americas Conference on Informasi systems.

Kotler 2002. Marketing management. New Delhi: Prentice Hall.

Morgan \& hunt 1994. The Commitment Trust of The Relationship Marketing Journal of Marketing, 58.

Poe3indriasAri. 2012. Pengertiankredibilitas-profesionalismeskeptisme-konservatisme-danintegritas. Diunduh 25/07/2015 2016.<http://poe3indriasari.word press.com/2012/10/20>

and business-to-business loyalty. Journal of Commerce.

Susanto \& Himawan 2004. Power. Jakarta: Branding. 
Ekonomika-Bisnis,Vol. 07 No. 02 Bulan Juli Tahun 2016 Hal 115-124

Tolga., D. 2009. Process to Create a Brand Personality and a Study on Brand Personality. İstanbul.

Wulan, A., EP, A. \& nurseto, s. 2014. Pengaruh nilai pelanggan dan citra merek terhadap loyalitas merek melalui kepercayaan merek sebagai variabel intervening pada notebook toshiba Jurnal sosial dan politik.

ZeIthaml, V. A., Berry L.L, Parasuraman, A., 1996. The Behavioral Consequences of Service Quality. Jurnal of Marketing 